\title{
Migration routes, behavior and protection status of Eurasian Spoonbills (Platalea leucorodia) wintering in China
}

Jire Xi ${ }^{1,2}$, Xueqin Deng ${ }^{2,3}$, Gerelt Zhao ${ }^{1}$, Nyambayar Batbayar ${ }^{4}$, Iderbat Damba ${ }^{9}$, Qingshan Zhao ${ }^{2,3}$, Shoubin Cui ${ }^{5}$, Chao Jiang ${ }^{5}$, Yiwen Chen ${ }^{2,6}$, Yat-tung Yu ${ }^{7}$, Lei Cao ${ }^{2,3^{*}}$ and Anthony David Fox ${ }^{8}$

\begin{abstract}
Background: The Eurasian Spoonbill (Platalea leucorodia) occurs throughout Eurasia and North and sub-Saharan Africa, with three recognized subspecies and six geographically distributed populations. However, in China, we knew almost nothing about migration routes, habitat use and effectiveness of current site protection measures for this species.

Methods: We deployed Global Positioning System/Global System for Mobile Communications (GPS/GSM) satellite trackers on 29 Eurasian Spoonbills captured in summer in Mongolia and northeastern China, to obtain complete migration routes data from 10 individuals from 19 complete migration episodes.
\end{abstract}

Results: Tracking data showed no geographical overlap during the annual cycle in Eurasian Spoonbills marked in the two main summering areas. Birds marked in the Naoli River Basin in Heilongjiang Province, China, wintered along the Jiangsu coastline in China, while Eurasian Spoonbills from two discrete summering areas (in Inner and western Mongolia) overwintered inland in the Yangtze River floodplain of China. Excluding the single Inner Mongolian bird, spring migration was significantly faster than autumn migration in the other two groups of birds. Eurasian Spoonbills mainly used water, wetland and grassland habitats in summer, but almost exclusively water in winter. Lack of protection of staging sites used by all the birds in spring and poor levels of protection throughout the annual cycle for western Mongolian birds (5-22\%) gives considerable cause for concern, although sites used in other time by East Mongolian and Naoli River birds in the rest of their annual life cycle enjoyed good levels of protection (49-95\%).

Conclusions: These results revealed previously unknown relationships between summering and wintering areas, migration routes and stopover sites for Eurasian Spoonbills wintering in China, suggesting the existence of discrete biogeographical population units. They also identified winter habitat use of Eurasian Spoonbills in China, confirming open water habitats as being critical throughout the annual cycle, although based on small sample size, gaps in current site safeguard networks for these populations.

Keywords: Biogeographical subpopulations, GPS/GSM loggers, Habitat use, Migration routes, Open water habitats, Site safeguard

\footnotetext{
${ }^{*}$ Correspondence: leicao@rcees.ac.cn

2 State Key Laboratory of Urban and Regional Ecology, Research

Center for Eco-Environmental Sciences, Chinese Academy of Sciences, Beijing 100085, China

Full list of author information is available at the end of the article
}

\section{Background}

Eurasian Spoonbills breed across Eurasia and winter in North Africa, sub-Saharan Africa and Eurasia, comprising three identified subspecies. These are: (1) a West African subspecies (Platalea leucorodia balsaci), original author(s) and the source, provide a link to the Creative Commons licence, and indicate if changes were made. The images or other third party material in this article are included in the article's Creative Commons licence, unless indicated otherwise in a credit line to the material. If material is not included in the article's Creative Commons licence and your intended use is not permitted by statutory regulation or exceeds the permitted use, you will need to obtain permission directly from the copyright holder. To view a copy of this licence, visit http://creativecommons.org/licenses/by/4.0/. The Creative Commons Public Domain Dedication waiver (http://creativeco mmons.org/publicdomain/zero/1.0/) applies to the data made available in this article, unless otherwise stated in a credit line to the data. 
which breeds mainly in Mauritanian and coastal islands (Piersma et al. 2012); (2) a Red Sea subspecies (P. $l$. archeri), which breeds in the Red Sea and along the coast of Somalia. The remainder are considered to belong to the nominate subspecies (3) the Eurasian Spoonbill $(P$. $l$. leucorodia) which is widely distributed throughout Eurasia. Within this third group, there are four accepted biogeographical populations (Wetlands International 2021): (1) a West Europe/West Mediterranean and West Africa population, which breeds along western coastal areas of Europe, winters in the western Mediterranean and the western coastal areas of Africa and is estimated to number 11,300 birds (Champagnon et al. 2019); (2) a Southeast European/Mediterranean and tropical African population, which winters in the Mediterranean or tropical northern Africa, estimated to number 11,700 birds (Champagnon et al. 2019); (3) a West/Southwest and South Asian population, which breeds extensively across Central and Southwest Asia, winters in Southwest and South Asia, and numbers some 23,000 individuals (Wetlands International 2021); and finally (4) an East Asian population, which breeds mainly in Northeast Asia, Mongolia and China, winters in Southeast China, South
Korea and Japan, which is thought to number 20,000 birds (Xi et al. 2021) (Fig. 1). Because of its extensive range, relative abundance and stable population trend, the Eurasian Spoonbill population is listed by Birdlife International (BirdLife International 2019) as a species of least concern (LC). However, we still know lamentably little about its flyway structure and the potential for small discrete elements of the species to be threatened because of its narrow feeding niche and reliance upon threatened and degrading wetlands.

There has been much research on the reproduction, feeding habits (Aguilera et al. 1996; Veen et al. 2012; Enners et al. 2020), migration (Jelena et al. 2012), home range and habitat selection (El-Hacen et al. 2013; Bellisario 2018) of European and African birds. In contrast, very few studies have taken place in East Asia, mainly concerning breeding and wintering (Li 2016), feeding habits and habitat use (Zhang 2018). So there is an urgent need to understand the relationships between breeding, staging and wintering areas used by birds to identify discrete biogeographical populations, establish effective monitoring programmes to determine trajectories in abundance and develop site safeguard and effective conservation

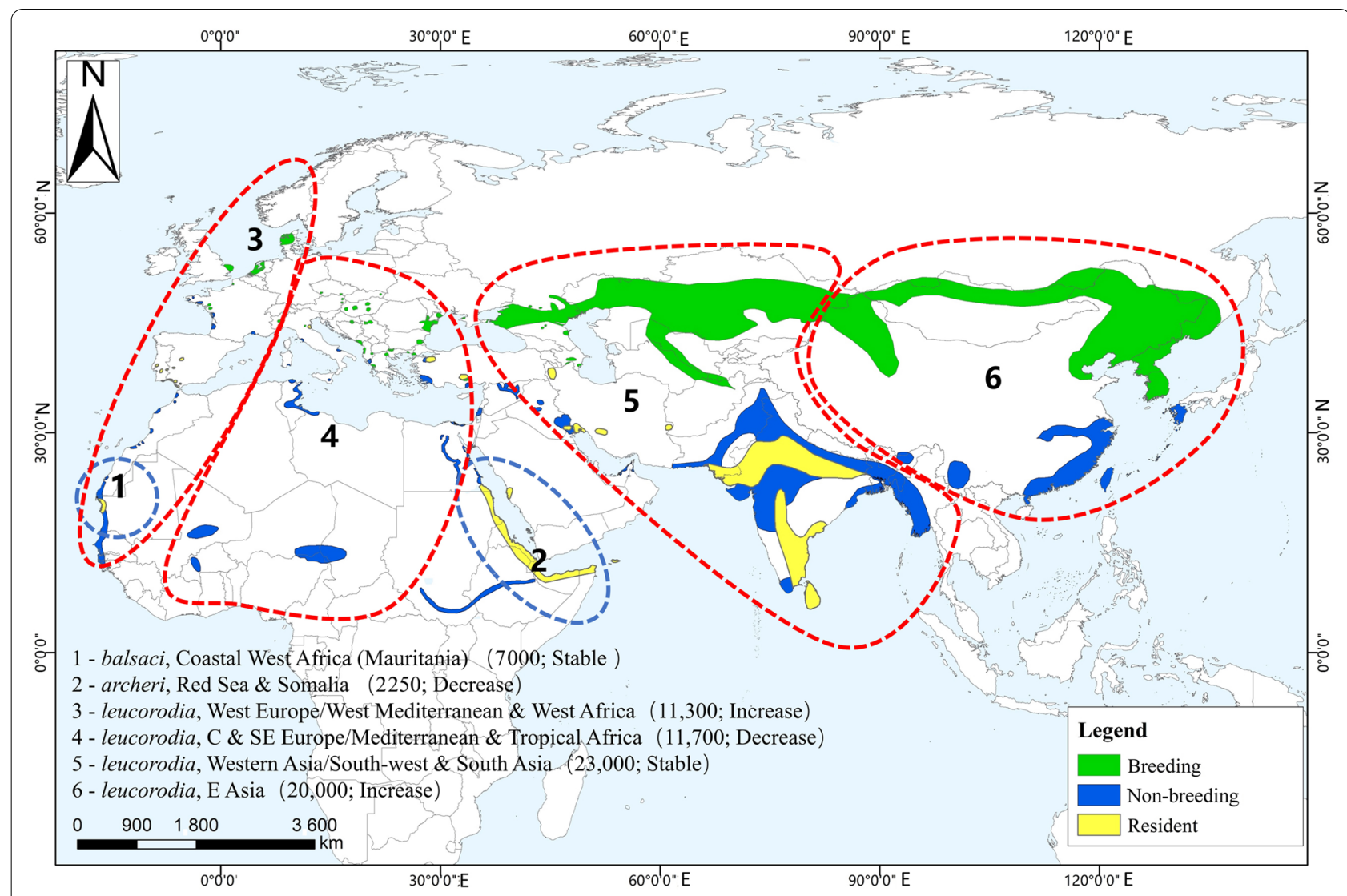

Fig. 1 World distribution map of the Eurasian Spoonbill (Platalea leucorodia) geographical population ( reproduced from Xi 2021) 
programmes for their protection. In this study, we report the first deployment of satellite tracking technology to study the migration of the Eurasian Spoonbill in East Asia, to establish the migration routes and strategy of the species, its habitat use and the degree of site safeguard currently in place to protect areas used along its regular migration corridors. Given the results of these studies, we provide recommendations to improve its conservation status in the future.

\section{Methods}

\section{Transmitter types and attachment}

Between July 2016 and August 2018, 29 Eurasian Spoonbills were captured at 3 separate locations on the summering areas (25 juveniles, 2 adults, 2 of unknown age, no birds were sexed in the field). Of these, 16 were caught in 2016 at Naoli River Basin $\left(46.73^{\circ} \mathrm{N}, 132.18^{\circ} \mathrm{E}\right.$; Qixinhe National Nature Reserve in Heilongjiang Province, China), 2 in 2017 at Hulun Lake $\left(48.93^{\circ} \mathrm{N}, 117.38^{\circ}\right.$ E; Inner Mongolia, China) and 11 in 2018 at Uvs Lake $\left(50.46^{\circ} \mathrm{N}, 93.10^{\circ} \mathrm{E}\right.$; Mongolia). We rounded up flightless pre-fledging juvenile birds and drove them onto movable funnel nets, deploying backpack trackers with solar cells to maintain battery power on the bird's backs using Teflon ribbon. We caught adults at roosting areas at night using spotlights. The 18 Eurasian Spoonbills captured in 2016 and 2017 were all fitted with backpack-mounted loggers from Hunan Global Messenger Co. Ltd, China (HQXS, weight 15-22 g). The 11 Eurasian Spoonbills captured in 2018 were fitted with backpack-mounted loggers from Ornitela, Lithuania (weight $25 \mathrm{~g}$ ). The tracking loggers collected location information via the Global Positioning System (GPS) and sent the data back to a server through a mobile communications network (GSM). In this study, the HQXS loggers collected 12 to 24 GPS positions per day, and the Ornitela loggers collected 24 to 144 GPS positions per day, the actual number of points depending on how much power remained in the tracker batteries.

Because of technical problems, 14 transmitters were lost (12 for HQXS and 2 for Ornitela, lost after 37-137 days on the breeding areas), no data were obtained from 4 transmitters (all Ornitela) and one bird either died or lost its transmitter in the breeding areas 27 days after catching. Lost devices or deaths of birds were determined based on total lack of movement registered by in-built accelerometers (Ornitela devices) or when a transmitter failed to move from its apparent position over 7 consecutive days (HQXS). Of the original 29 Eurasian Spoonbills, 10 individuals provided full information from at least one complete spring or autumn migration (Additional file 1: Table S1), generating a total of 19 complete migration routes obtained through tracking. Eight of the analyzed individuals were marked as juveniles and as Eurasian Spoonbills only starts breeding at age of 3 years, we accept that these birds in their sub-adult summers would be less loyal to specific breeding localities than the adult birds (Pigniczki and Vegvari 2015). The multi-year migration route data from these 10 individuals form the basis for the analysis in this study. Information on the individual birds and their loggers is summarized in Additional file 1: Table S1.

\section{Defining migration periods}

We wrote simple routines in $\mathrm{R}$ ( $\mathrm{R}$ development core team 2020 ) to delete GPS locations with null values or inadmissible coordinates. We used Wang et al's (2018) first passage time method to differentiate the migration periods when each bird could be categorized into "fly" and "non-fly" behavior. Any "non-fly" state lasting for more than 2 days (48 h; Koelzsch et al. 2016) within an activity radius less than $50 \mathrm{~km}$ was defined as staging at a stopover site and the number of discrete stopover sites was calculated accordingly. Throughout this paper, we define autumn migration as starting with the first "fly" state shown by an individual departing the summering site and the first "non-fly" state of that individual arriving at the wintering site. Spring migration was defined as extending from the first "fly" status of an individual leaving the wintering site until the first "non-fly" status of that individual after arrival at the summering site. The summering points was defined as the GPS location from the end of the spring migration to the beginning of the autumn migration.

\section{Defining migration parameters}

We here define nine migration parameters for each individual migration episode as follows. The migration start time was defined as the time when the tracked individual clearly left the summering/wintering ground based on attaining its first "fly" status. That migration episode ended when the same individual arrived at the wintering/summering site when the first "non-fly" status was recorded (Wang et al. 2018). We defined duration of migration as the difference between these two times, i.e. between the beginning and the end of a full migration episode (including the time at stopover sites). The number of stopover sites was defined as the number of times the tracked individual used separate stopover sites (as defined above) and stopover duration was the cumulative sum of all time spent at the stopover sites throughout the migration episode. Migration distance refers to all the cumulative "fly" distances taken by a tracked individual during a migration episode, excluding the distance flown during activities at stopover sites. The migration speed is the overall average speed of the tracked individual in 
the migration process, the value obtained by dividing the migration distance by the migration duration. The daily travel speed is calculated as the migration distance divided by the "fly" time (the migration duration minus the rest duration) (Nilsson et al. 2013). We calculated the Straightness Index as the ratio of the difference in distance between the straight-line distance between the start and end points of migration and the actual route taken by each bird (Benhamou 2004). Based on the data size and the similarity of migration routes of the tracked individuals, we used Wilcoxon rank-sum test to compare the parameters of autumn migration between two groups of birds, which were differentiated by their migration routes. Values are given as mean \pm standard deviation, unless otherwise stated.

In order to get a clearer understanding of the stopover sites of the Eurasian Spoonbill during the spring and autumn migration, we also counted the number of sites where the stopover duration was longer than $6 \mathrm{~h}$ (but less than $48 \mathrm{~h}$ ) and where the range of activity was within $30 \mathrm{~km}$. These we named "stop sites" where spoonbills could potentially drink, rest, preen and feed to a limited extent, to be distinguished from "stopover sites" defined above, where prolonged stopover duration imply great nutritional and energetic benefit.

\section{Quantifying habitat use}

We used the tracking data from the ten Eurasian Spoonbills whilst they were at rest to determine the habitat use of these individuals during summer and winter. We extracted "non-fly" segments from the tracking data and overlaid these positions on land cover data within ArcGIS 10.3. We used the $10-\mathrm{m}$ resolution global land cover raster layer released by Tsinghua University in 2017 (used to analyze the land cover types outside China) (Gong et al. 2019 ) and the $30-\mathrm{m}$ resolution national land cover raster layer within China in 2015 as base maps. We merged second level land use types from 2015 data (based on the FROM-GLC-Hierarchy) into first-level types to harmonize with the 2017 data, resulting in ten land cover types: including cropland (including rice fields), forest, grassland, shrubland, wetland, water, tundra, impervious surface, bare land, snow/ice (http://data.ess.tsinghua.edu. $\mathrm{cn} /)$.

\section{Establishing degree of protected area use}

Finally, to determine the extent to which the tagged wintering Eurasian Spoonbills used the existing protected area network, we overlaid the "non-fly" stationary positions from the tagged birds upon the world natural reserve boundary data (UNEP WCMC 2017) and China's national nature reserve boundary data (http://www. resdc.cn/) within the ArcGIS 10.3 environment.

\section{Results}

Chinese wintering birds originate from at least three breeding areas

Based on the tracking data, Eurasian Spoonbills from the three different breeding provenances migrated separately to winter in two different parts of China. The four tagged birds that were marked in the Naoli River Basin (Heilongjiang Province, China) all wintered in coastal China (including around Yancheng, Lianyungang and Tai Lake in Jiangsu Province; Fig. 2). The remaining six birds caught at Uvs Lake (in western Mongolia) or Hulun Lake (in eastern Inner Mongolia) wintered in the middle and lower reaches of the Yangtze River floodplain, in Hubei, Jiangxi and Anhui Provinces (Fig. 3).

\section{Autumn migration routes}

We derived 13 complete autumn migrations from the 10 tagged Eurasian Spoonbills. Four tracked Eurasian Spoonbills (ES01, ES02, ES03, ES04) captured along the Naoli River Basin, Heilongjiang Province used Ussuri Bay (Primorsky Krai, Russia), Kanghwa Bay (Inchon, South Korea) or Haizhou Bay (Lianyungang, Jiangsu Province, China) as stopover sites (Fig. 2; Additional file 1: Table S2) and wintered along the Jiangsu coast. The mean migration distance was $2376 \pm 161 \mathrm{~km}$ (standard deviation, SD).

The group that overwintered in the Yangtze River floodplain of China, originated from two different, but more westerly summering areas. The single tagged Eurasian Spoonbill (ES05) from the Wulanor wetland on Hulun Lake, Inner Mongolia departed and stopped at the Daling River (Chaoyang, Liaoning Province, China) and the Yellow River Delta in Bohai Bay during its autumn migration, and wintered at Poyang Lake in the Yangtze River Basin (Fig. 3; Additional file 1: Table S2). The migration distance was $2451 \mathrm{~km}$. Complete migration data were available from five individuals (ES06, ES07, ES08, ES09, ES10) marked at Uvs Lake in western Mongolia. These birds commenced autumn migration from their summering habitat, stopping either in southern Mongolia, in the Yellow River Basin (Inner Mongolia and Shaanxi and Henan Provinces) or within the Yangtze River Basin (Hubei and Anhui Provinces). Of all these staging areas, the Yellow River Basin formed the core area for all the migration routes used by this group of birds from western Mongolia. The wintering areas of these birds were Poyang Lake (ES09), Dongting Lake (ES06, ES07), Liangzi Lake (ES08) and Caizi Lake (ES10) in the Yangtze River Basin in 2018/2019 winter (Fig. 3; Table 1). Their mean migration distance was $3466 \pm 527 \mathrm{~km}(\mathrm{SD})$. Unfortunately, the signal from ES09 was lost in December 2018 in Inner Mongolia, China, and ES10 died or lost the transmitter in May 2019 in Anhui Province, China, 


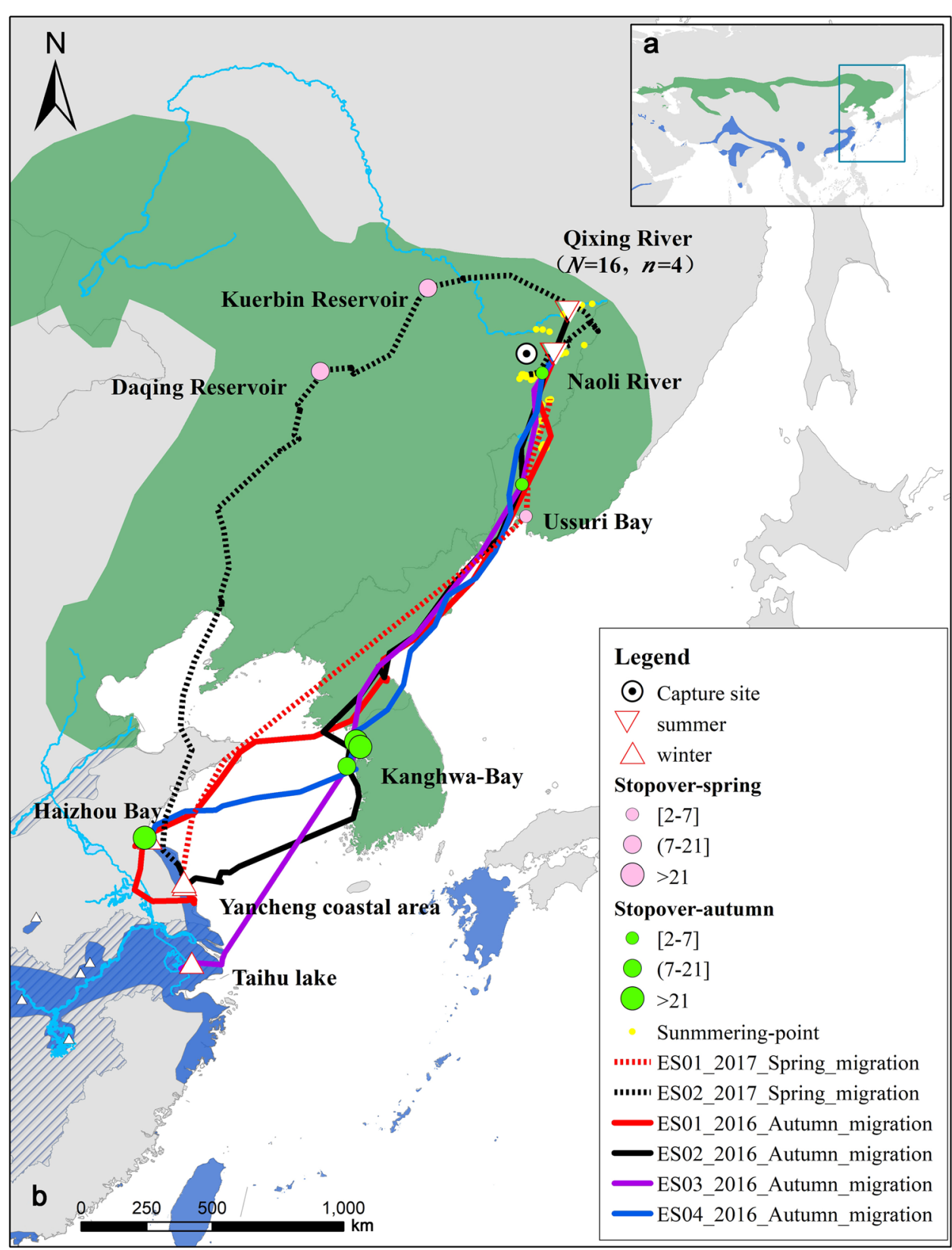

Fig. 2 a East Asia map of the breeding (green) and wintering (blue) distribution of the Eurasian Spoonbill. b Enlarged map of the same detailed wintering area in China coast, showing autumn migration routes ( $N=4$ and stopover sites in green) and spring migration routes $(N=2$ and stopover sites in pink). Circles with central black dots indicate capture sites, inverted triangles summering sites, regular triangles wintering sites and yellow dots show areas used during summer. The distribution data of the Eurasian Spoonbill are derived from Xi (2021)

which was close to its wintering area. Data from the remaining birds in subsequent years showed that these birds summered at Uvs Lake (western Mongolia), the Zavkhan and Ider Rivers, with one individual spending the summer on the Tuin River in central Mongolia (Fig. 3; Additional file 1: Table S2).
Three tagged juveniles hatched in western Mongolia (ES06, ES07, ES08) in 2018 changed their subsequent summer location (Fig. 3; Additional file 1: Table S2). In 2019, the three birds shifted their summer quarters from western Mongolia to central Mongolia and the Yellow River Basin (about $1300 \mathrm{~km}$ ). Two of them 


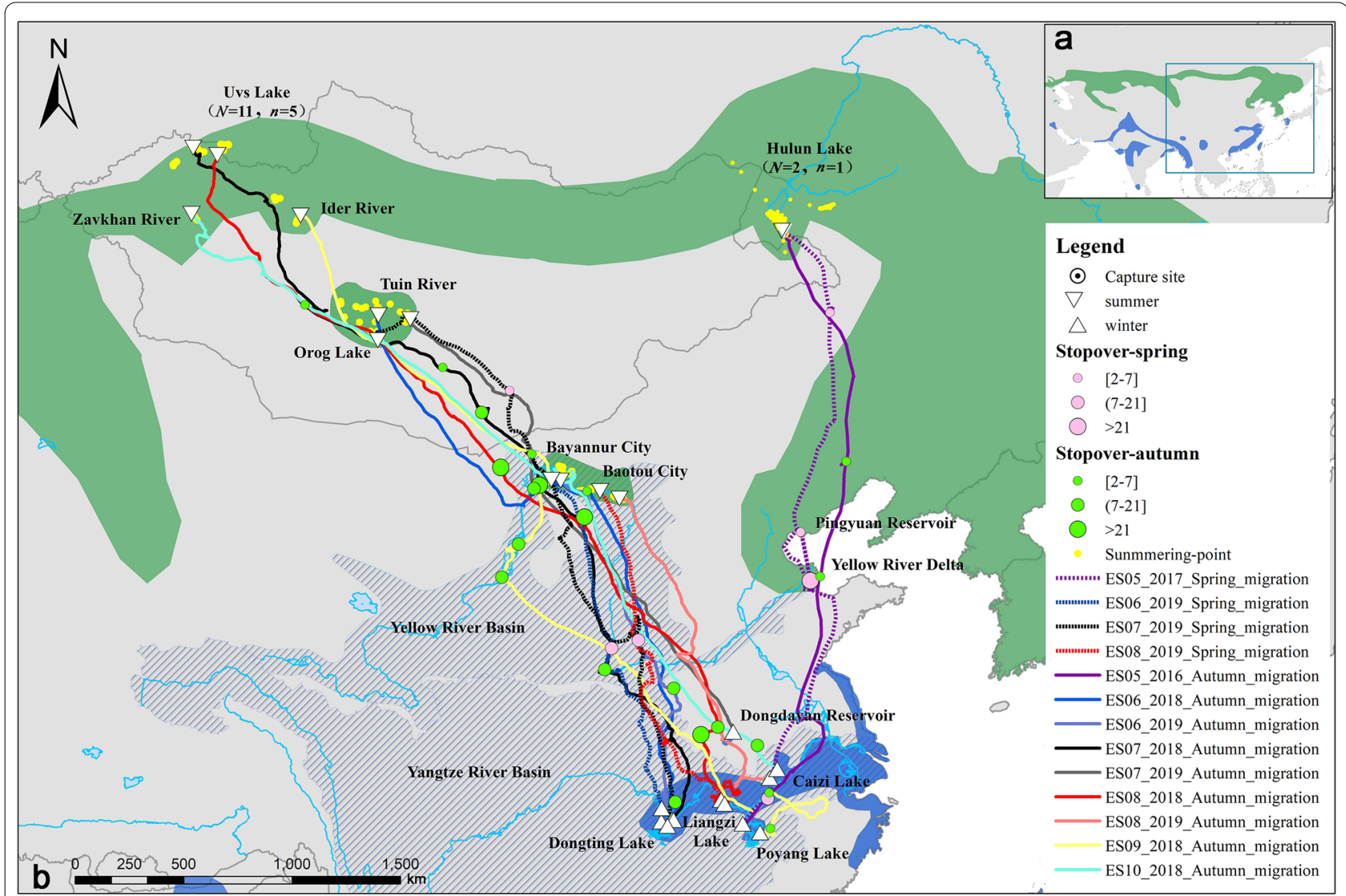

Fig. 3 a East Asia map of the breeding (green) and wintering (blue) distribution of the Eurasian Spoonbill. $\mathbf{b}$ Enlarged map of the same detailed wintering inland in China, showing the dichotomy between birds breeding in western Mongolia (autumn migration routes $(N=8)$; spring migration routes $(N=3)$ ) and that caught at Hulun Lake, Inner Mongolia (autumn migration routes $(N=1)$; spring migration routes $(N=1)$ ). Circles with central black dots indicate capture sites, inverted triangles summering sites, regular triangles wintering sites and yellow dots show areas used during summer, the black cross-hatched area represents the Yellow River Basin and the Yangtze River Basin. The distribution data of the Eurasian Spoonbill are derived from Xi (2021)

(ES07, ES08) also changed their wintering location after autumn 2019. ES07 wintered at Dongting Lake, Hunan Province in the Yangtze in 2018/2019 but wintered in Henan Province in 2019/2020 (about $400 \mathrm{~km}$ to the east; Additional file 2: Fig. S2). ES08 wintered on Caizi Lake, Anhui Province in 2019/2020 winter after wintering at Liangzi Lake, Hubei Province (although both sites are within the Yangtze, c. $250 \mathrm{~km}$ apart) in 2018/2019 winter (Additional file 2: Fig. S3). In summary, all three surviving juveniles changed their summer places and shortened their migration distance.

\section{Spring migration routes}

We derived six complete spring migration episodes in 2019 from the ten Eurasian Spoonbills. Only two of the tagged Eurasian Spoonbills, which wintered along the coast at Yancheng, Jiangsu Province, survived to spring. They followed different spring migration routes but to the same ultimate summering area (along the Naoli River, near Shuangyashan City, Heilongjiang Province, China; Fig. 2; Table 1). ES01 flew along the coast, and staged for 2 days in Ussuri Bay (Primorsky Krai), Russia, while ES02 flew inland and staged for 22 days at Daqing and Kuerbin Reservoirs in Yichun, Heilongjiang Province, China. The mean migration distance was $2432 \pm 590 \mathrm{~km}(\mathrm{SD})$.

The lone Inner Mongolian tagged individual, ES05, started its spring migration from its wintering site at Poyang Lake in the Yangtze River Basin, and staged at Bohai Bay and a reservoir in Tangshan, Hebei Province between 28 February and 12 April, before continuing back to Hulun Lake via Pingyuan Reservoir (Hebei Province; Fig. 3; Table 1). The migration distance was $2452 \mathrm{~km}$.

Of the western Mongolian tagged birds, ES06, ES07 and ES08 commenced spring migration from the Yangtze River Basin (Fig. 3; Table 2), ES06 stopped midway in the Yellow River Basin (Shaanxi Province) for about 10 days, before returning to its summering area in the 


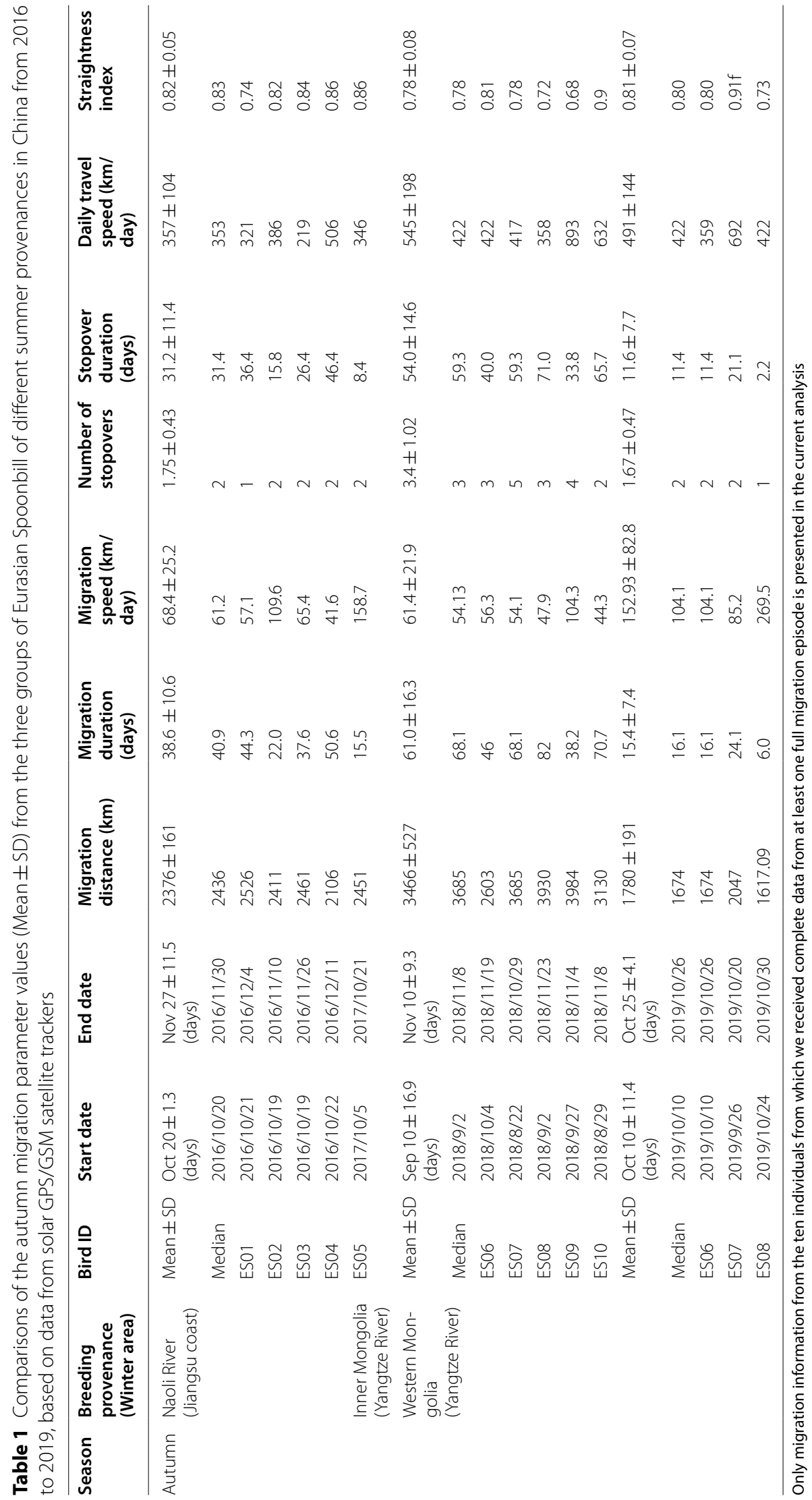




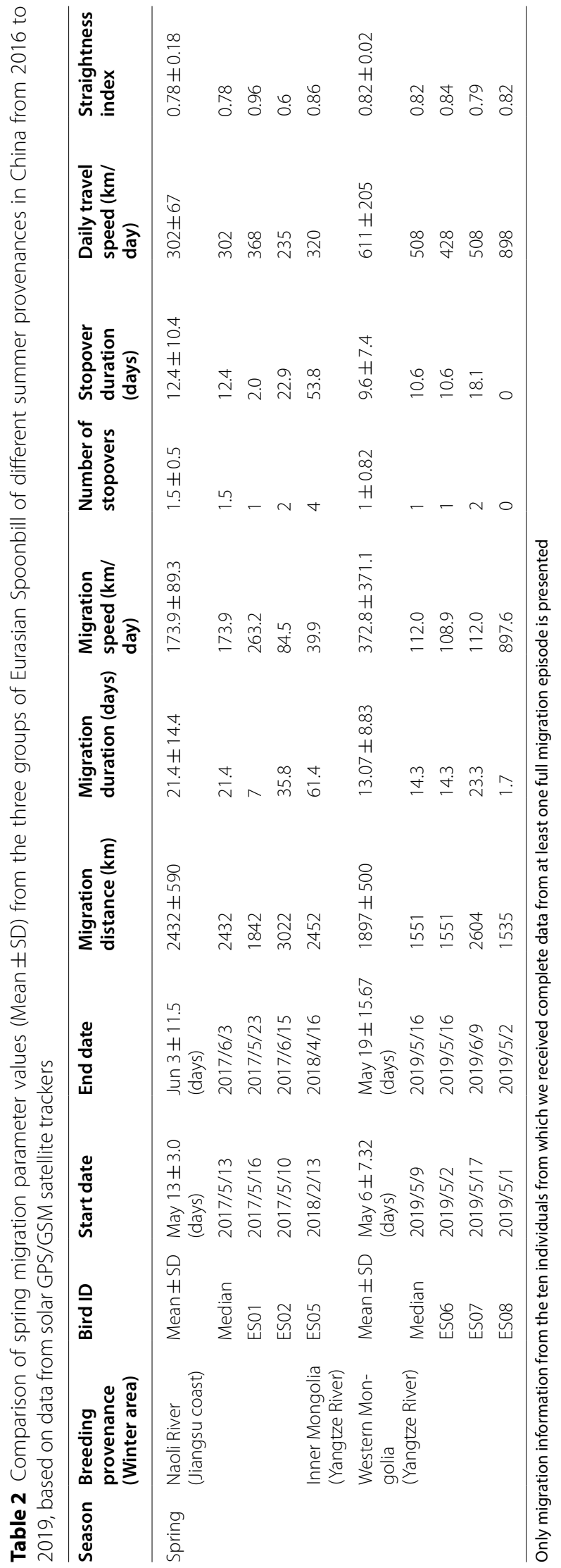


Yellow River Basin, Bayannur, Inner Mongolia (Additional file 2: Figure S1). ES07 staged in the Yellow River Basin (Shanxi Province) for about 15 days and 2 further days in the southern Gobi region of Mongolia, finally summering along the Tuin River in central Mongolia. ES08 flew from its Dongting Lake wintering site directly to its summering place in the Yellow River Basin (Baotou, Inner Mongolia) without stopping (Fig. 3; Table 2). The mean migration distance was $1897 \pm 500 \mathrm{~km}(\mathrm{SD})$.

\section{Autumn migration parameters}

We summarized migration parameters in different migration routes (Table 1), as we tagged only one bird in Inner Mongolia, China, here we only make comparisons between birds caught along the Naoli River in Heilongjiang Province, China, and those in western Mongolia.

Among these birds, autumn migration started from late August to the end of October. Naoli River individuals left their summering area in mid-October, arriving to their coastal Jiangsu Province wintering areas in late November to mid-December. All Naoli River birds left their breeding areas more or less simultaneously in 2016 between 19 and 22 October. Western Mongolian birds left their summer areas earlier between 22 August and 5 October in 2017 and 2018. However, the same individuals left later in 2019, when they also arrived at their ultimate wintering site significantly earlier in later October compared to 2018, when almost all arrived in November. This was because they undertook a much shorter overall migration in that year, having summered at sites well south of where they had previously been captured. In 2019, three western Mongolian individuals did not return to their place of hatching, so their migration distance was almost half of that in autumn 2018 (Table 1).

Naoli River birds undertook significantly shorter migration routes than western Mongolian tagged birds (Wilcoxon rank-sum test, $P<0.05$ ) but the difference in migration duration did not differ significantly (Table 3 ). Western Mongolia tagged birds made twice the number of stopovers taken by Naoli River birds (a statistically significant difference, Wilcoxon rank-sum test, $P<0.05$ ) although the stopover duration did not differ significantly between the two groups (Table 3). Overall, migration speed, daily travel speed and straightness index did not differ between the two routes.

\section{Spring migration parameters}

The start of Far East Asian Eurasian Spoonbill spring migration extended from mid-February to mid-May (Table 2). Naoli River tagged individuals left their coastal wintering area between 10 and 16 May and arrived at their summering areas between 23 May and 15 June.
Western Mongolian tagged birds started migration between 1 and 17 May, arriving at the summering areas between 2 May and 9 June (Table 2), which did not differ significantly from Naoli River tagged individuals. Overall, migration distance, daily travel speed and straightness index did not differ between the two routes.

In contrast, the single tagged in Inner Mongolia began spring migration on 13 February and arrived at the summering area on 16 April (Table 2), a migration duration of 61.4 days, significantly greater than all other individuals, due to more frequent stopovers and longer stopover duration.

\section{Stop sites}

We identified 45 stop sites, including 35 during autumn migration and 10 during spring migration. None of these stop sites used in autumn were used as stop sites by any individuals again in the following spring migration, suggesting these were of less importance than stopover sites. Among them, Mongolia (11 sites) and Henan Province (7 sites), China, and Inner Mongolia (7 sites) of China were the most used areas (Table 4).

\section{Habitat use}

Habitat use differed between migration routes (Figs. 4, 5, 6; Additional file 1). Throughout the annual cycle, more than $90 \%$ of habitat types used by Eurasian Spoonbills tracked in Naoli River were wetlands and open waters combined. The same was true for the single Inner Mongolian tagged bird, except at spring stopover areas, where it exploited $49 \%$ cropland. Western Mongolian tagged birds used 19-25\% cropland throughout the year and $34 \%$ grassland in summer, proportionally less open water (varying between $74 \%$ in winter and $31 \%$ in summer).

\section{Use of protected areas}

All tagged individuals used spring stopover sites that lacked protection (Fig. 7; Additional file 1: Table S4). Naoli River and the Inner Mongolian birds used sites throughout the rest of their annual life cycle which seemed well protected ( $>49 \%)$. Birds tagged in western Mongolia also exploited areas that were relatively poorly protected (19-21\% for summering and wintering areas, but only $5 \%$ for autumn stopover areas).

Naoli River tagged Eurasian Spoonbills spent $73.0 \%$ of time on summering sites located within protected areas (Fig. 7; Additional file 1: Table S4), mostly in the Naoli River and Sanjiang National Nature Reserves. During autumn migration, these birds spent $62.0 \%$ of their stopover time within the Xingkai Lake National Nature Reserves, and $80.9 \%$ of time on wintering sites within the Yancheng National Nature Reserve. 
Table 3 Comparison and Wilcoxon rank-sum test results of migration parameters (Mean \pm SD) of Eurasian Spoonbills from Naoli River, China in 2016 and western Mongolia in 2018

\begin{tabular}{|c|c|c|c|c|c|c|}
\hline \multirow[t]{2}{*}{ Migration parameters } & \multicolumn{2}{|c|}{$\begin{array}{l}\text { Naoli River China } \\
\text { Autumn }(2016)(N=4)\end{array}$} & \multicolumn{2}{|c|}{$\begin{array}{l}\text { Western Mongolia } \\
\text { Autumn }(2018)(N=5)\end{array}$} & \multicolumn{2}{|c|}{$\begin{array}{l}\text { Results of } \\
\text { Wilcoxon } \\
\text { rank-sum test } \\
\text { for differences } \\
\text { between means }\end{array}$} \\
\hline & Mean \pm SD & Median & Mean \pm SD & Median & $w$ & $P$ \\
\hline Start date & Oct $20 \pm 1.3$ (days) & $2016 / 10 / 20$ & Sep $10 \pm 16.9$ (days) & 2018/9/2 & - & - \\
\hline End date & Nov $27 \pm 11.5$ (days) & $2016 / 11 / 30$ & Nov $10 \pm 9.3$ (days) & 2018/11/8 & - & - \\
\hline Migration distance (km) & $2376 \pm 161$ & 2436 & $3466 \pm 527$ & 3685 & 0 & 0.0159 \\
\hline Migration duration (days) & $38.6 \pm 10.6$ & 40.9 & $61.0 \pm 16.3$ & 68.1 & 3 & 0.1111 \\
\hline Migration speed (km/day) & $68.4 \pm 25.3$ & 61.2 & $61.4 \pm 21.9$ & 54.1 & 13 & 0.5556 \\
\hline Number of stopovers & $1.75 \pm 0.43$ & 2.0 & $3.4 \pm 1.02$ & 3.0 & 1.5 & 0.0398 \\
\hline Stopover duration (days) & $31.2 \pm 11.4$ & 31.4 & $54.0 \pm 14.6$ & 59.3 & 3 & 0.1111 \\
\hline Daily travel speed (km/day) & $358 \pm 104$ & 353 & $545 \pm 198$ & 422 & 4 & 0.1905 \\
\hline Straightness index & $0.82 \pm 0.05$ & 0.83 & $0.78 \pm 0.08$ & 0.78 & 14 & 0.4127 \\
\hline
\end{tabular}

The tracked Inner Mongolia Eurasian Spoonbill spent 94.8\% of time within protected areas during the summer period (Fig. 7; Additional file 1: Table S4), almost all within the Hulun Lake and Hui River National Nature Reserves. During autumn stopovers, $48.5 \%$ of positions were located within Yellow River Delta National Nature Reserve, and $70.8 \%$ in winter period, the majority from the Poyang Lake National Nature Reserve (Fig. 7; Additional file 1: Table S4).

Tracking positions from western Mongolia Eurasian Spoonbills on the summering grounds were relatively rarely (19.2\%) from within Uvs Nuur Basin Biosphere Reserve and Valley of Lake Reserve, and just $4.9 \%$ of the sites used as autumn stopover sites fell within Ordos Relict Gull National Nature Reserve. In winter, $21.8 \%$ of the sites were located in protected areas, mainly within East Dongting Lake National Nature Reserve, Shengjin Lake National Nature Reserve, Poyang Lake National Nature Reserve and Tongling Freshwater Dolphin National Nature Reserve.

\section{Discussion}

We used satellite tracking technology for the first time to reveal migration routes of Eurasian Spoonbills wintering in China and to highlight total separation in migration routes in spring and autumn between coastal and inland wintering birds of differing breeding provenances. Although our sample size is modest, it appears that Eurasian Spoonbills wintering in the freshwater Yangtze River Wetlands breed further to the west into western Mongolia steppe than spoonbills wintering in coastal wetlands in China and these sets of birds have migration routes and important stopovers that appear independent of each other.

Although these results come from the first telemetry tagging of this species in Far East Asia, we should be prudent about concluding too much from so few individuals from relatively few sites and from relative few years. For example, the majority of Eurasian Spoonbills marked in this study were caught as juveniles, which are highly unlikely to behave as adults. Eurasian Spoonbills breed first when aged three years old, and studies show that adult birds are more loyal to their breeding area than the young birds, which may summer well away from natal areas (Lok et al. 2011). This was very evident from our data, which showed that several of our tagged Eurasian Spoonbills returned in spring along their autumn corridor, but did not travel all the way to their natal summering area, stopping short in wetlands well to the south of the original nesting areas. Hence, three tagged birds (ES06, ES07, ES08) marked as birds of the juveniles failed to return to their place of hatching the following spring.

There is also evidence from studies of Eurasian Spoonbills in other parts of the range that birds are more likely to change their wintering area in their second winter (Lok et al. 2011), and juvenile birds are more likely to disperse and exploit new habitats (Pigniczki and Vegvari 2015), which is consistent with our results. Clearly, we need many more replicates of such individual tracking to gather more evidence on levels of breeding and winter site fidelity before we can judge the loyalty of individuals to specific sites throughout the annual cycle, especially how this change with age and pairing status. Although most individuals followed very similar migration routes between breeding and wintering areas, the precise routes 
Table 4 The stop sites of the Eurasian Spoonbill in the spring and autumn migration (the stopover duration is $6-48 \mathrm{~h}$ and the range of activity is greater than $30 \mathrm{~km}$ )

\begin{tabular}{|c|c|c|c|c|c|c|c|c|}
\hline Bird ID & Year & Season & Star date & End date & $\begin{array}{l}\text { Stopover } \\
\text { duration } \\
\text { (h) }\end{array}$ & Longitude & Latitude & Location \\
\hline \multirow[t]{3}{*}{ ES01 } & 2016 & Autumn & 2016/10/24 & $2016 / 10 / 25$ & 12.0 & 122.45 & 37.12 & Rongcheng City, Weihai City, Shandong Province \\
\hline & & & 2016/12/4 & 2016/12/4 & 12.0 & 120.57 & 33.59 & Tinghu District, Yancheng City, Jiangsu Province \\
\hline & 2017 & Spring & $2017 / 5 / 21$ & $2017 / 5 / 23$ & 45.1 & 132.29 & 43.31 & Gorod Artem, Primorsky Krai, Russia \\
\hline \multirow[t]{3}{*}{ ESO2 } & 2017 & Spring & $2017 / 5 / 15$ & $2017 / 5 / 16$ & 21.1 & 123.85 & 44.91 & Qian'an County, Songyuan City, Jilin Province \\
\hline & & & $2017 / 5 / 17$ & 2017/5/17 & 15.1 & 124.50 & 45.98 & Datong District, Daqing City, Heilongjiang Province \\
\hline & & & $2017 / 6 / 14$ & $2017 / 6 / 14$ & 18.0 & 133.01 & 47.12 & Fujin City, Jiamusi City, Heilongjiang Province \\
\hline \multirow[t]{2}{*}{ ESO3 } & 2016 & Autumn & 2016/10/21 & 2016/10/21 & 12.0 & 132.62 & 45.59 & Hulin City, Jixi City, Heilongjiang Province \\
\hline & & & 2016/10/27 & 2016/10/28 & 14.9 & 130.70 & 42.33 & Khasansky District, Primorsky Krai, Russia \\
\hline \multirow[t]{2}{*}{ ES05 } & 2017 & Autumn & 2017/10/6 & 2017/10/6 & 10.1 & 120.49 & 44.00 & Aluhorqin Banner, Chifeng City, Inner Mongolia \\
\hline & & & 2017/10/17 & 2017/10/18 & 47.0 & 117.92 & 31.10 & $\begin{array}{l}\text { Xingou West Road, Wuwei County, Wuhu City, Anhui } \\
\text { Province }\end{array}$ \\
\hline \multirow[t]{11}{*}{ ES06 } & 2018 & Autumn & 2018/10/4 & 2018/10/5 & 19.9 & 100.86 & 45.08 & Bogd, Bayankhongor, Mongolia \\
\hline & & & 2018/10/6 & 2018/10/7 & 23.0 & 107.16 & 40.46 & Hangjin Banner, Ordos City, Inner Mongolia \\
\hline & & & 2018/10/26 & 2018/10/26 & 7.9 & 106.98 & 40.24 & Dengkou County, Bayannaoer City, Inner Mongolia \\
\hline & & & 2018/11/4 & 2018/11/5 & 17.0 & 107.47 & 40.70 & Linhe District, Bayannur City, Inner Mongolia \\
\hline & & & 2018/11/8 & 2018/11/9 & 13.0 & 112.61 & 34.85 & Mengjin County, Luoyang City, Henan Province \\
\hline & & & 2018/11/9 & 2018/11/10 & 7.0 & 112.77 & 32.67 & Tanghe County, Nanyang City, Henan Province \\
\hline & & & 2018/11/10 & 2018/11/10 & 12.0 & 112.68 & 31.47 & Zhongxiang City, Jingmen City, Hubei Province \\
\hline & 2019 & Spring & $2019 / 5 / 2$ & 2019/5/3 & 7.9 & 110.74 & 34.64 & Lingbao City, Sanmenxia City, Henan Province \\
\hline & & & 2019/5/3 & 2019/5/4 & 20.9 & 110.30 & 35.04 & Heyang County, Weinan City, Shaanxi Province \\
\hline & & & 2019/5/4 & 2019/5/4 & 16.1 & 110.53 & 35.50 & Wanrong County, Yuncheng City, Shanxi Province \\
\hline & & Autumn & 2019/10/11 & 2019/10/11 & 18.0 & 111.89 & 35.10 & Yuanqu County, Yuncheng City, Shanxi Province \\
\hline \multirow[t]{10}{*}{ ESO7 } & 2018 & Autumn & 2018/8/29 & 2018/8/30 & 16.1 & 97.49 & 46.27 & Delger, Govi Altai, Mongolia \\
\hline & & & $2018 / 8 / 30$ & 2018/8/31 & 17.0 & 97.72 & 46.15 & Delger, Govi Altai, Mongolia \\
\hline & & & 2018/8/31 & 2018/9/1 & 18.0 & 100.84 & 45.05 & Bogd, Bayankhongor, Mongolia \\
\hline & & & 2018/9/13 & 2018/9/14 & 20.9 & 105.35 & 43.06 & Norgon, Omnogovi, Mongolia \\
\hline & & & 2018/10/15 & 2018/10/15 & 11.0 & 109.34 & 39.58 & Yijinhuoluo Banner, Ordos City, Inner Mongolia, China \\
\hline & & & 2018/10/16 & 2018/10/16 & 11.0 & 110.44 & 35.32 & Wanrong County, Yuncheng City, Shanxi Province, China \\
\hline & & & 2018/10/27 & 2018/10/27 & 13.0 & 112.99 & 32.28 & Zaoyang City, Xiangyang City, Hubei Province, China \\
\hline & & & 2018/10/28 & 2018/10/29 & 23.0 & 113.37 & 31.85 & Zengdu District, Suizhou City, Hubei Province, China \\
\hline & 2019 & Spring & $2019 / 6 / 4$ & 2019/6/4 & 21.1 & 108.78 & 39.46 & Etuoke Banner, Ordos City, Inner Mongolia, China \\
\hline & & & 2019/6/8 & 2019/6/9 & 17.0 & 102.05 & 45.81 & $\begin{array}{l}\text { Baruunbayan-Ulaan, Khairkhandulaan, Ovorkhangai, } \\
\text { Mongolia }\end{array}$ \\
\hline \multirow[t]{11}{*}{ ES08 } & 2018 & Autumn & 2018/9/2 & 2018/9/3 & 31.9 & 95.75 & 47.56 & Aldar, Zavkhan, Mongolia \\
\hline & & & 2018/9/4 & 2018/9/5 & 16.1 & 97.47 & 46.31 & Delger, Govi Altai, Mongolia \\
\hline & & & 2018/9/5 & 2018/9/6 & 12.0 & 103.93 & 42.81 & Khurmen, Omnogovi, Mongolia \\
\hline & & & $2018 / 9 / 28$ & 2018/9/29 & 14.2 & 109.40 & 39.37 & Yijinhuoluo Banner, Ordos City, Inner Mongolia, China \\
\hline & & & 2018/11/18 & 2018/11/19 & 24.0 & 114.36 & 32.00 & Luoshan County, Xinyang City, Henan Province, China \\
\hline & & & 2018/11/19 & 2018/11/19 & 6.2 & 115.56 & 30.30 & Qichun County, Huanggang City, Hubei Province, China \\
\hline & & & 2018/11/20 & $2018 / 11 / 22$ & 46.1 & 115.23 & 30.12 & Yangxin County, Huangshi City, Hubei Province, China \\
\hline & 2019 & Autumn & 2019/10/24 & 2019/10/25 & 28.6 & 113.18 & 35.17 & Bo'ai County, Jiaozuo City, Henan Province, China \\
\hline & & & 2019/10/26 & 2019/10/26 & 20.4 & 113.58 & 34.95 & Huiji District, Zhengzhou City, Henan Province, China \\
\hline & & & 2019/10/27 & $2019 / 10 / 28$ & 25.9 & 115.05 & 32.25 & Huangchuan County, Xinyang City, Henan Province, China \\
\hline & & & 2019/10/28 & 2019/10/29 & 27.1 & 115.60 & 30.59 & Xishui County, Huanggang City, Hubei Province, China \\
\hline ESO9 & 2018 & Autumn & 2018/10/22 & $2018 / 10 / 22$ & 13.9 & 115.42 & 30.13 & Qichun County, Huanggang City, Hubei Province, China \\
\hline \multirow[t]{2}{*}{ ES10 } & 2018 & Autumn & $2018 / 8 / 30$ & 2018/9/1 & 28.8 & 96.11 & 46.98 & Jargalan, Govi Altai, Mongolia \\
\hline & & & 2018/9/1 & $2018 / 9 / 2$ & 17.0 & 100.86 & 45.06 & Bogd, Bayankhongor, Mongolia \\
\hline
\end{tabular}




\section{Coastal wintering population}
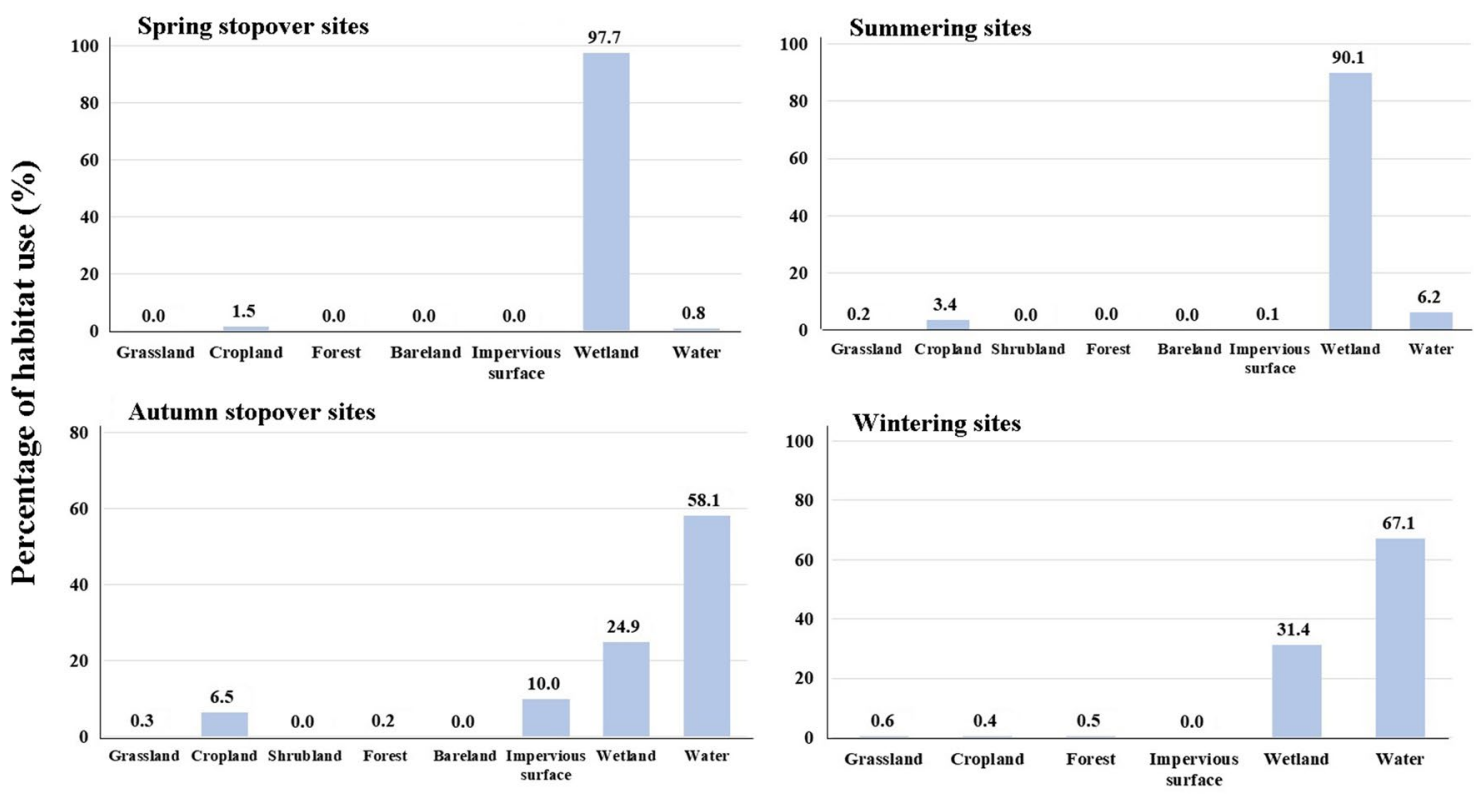

Habitat use types

Fig. 4 Habitat use of the Eurasian Spoonbill wintering along the coast of China in their spring migration stopover sites, summering sites, autumn migration stopover sites and wintering sites
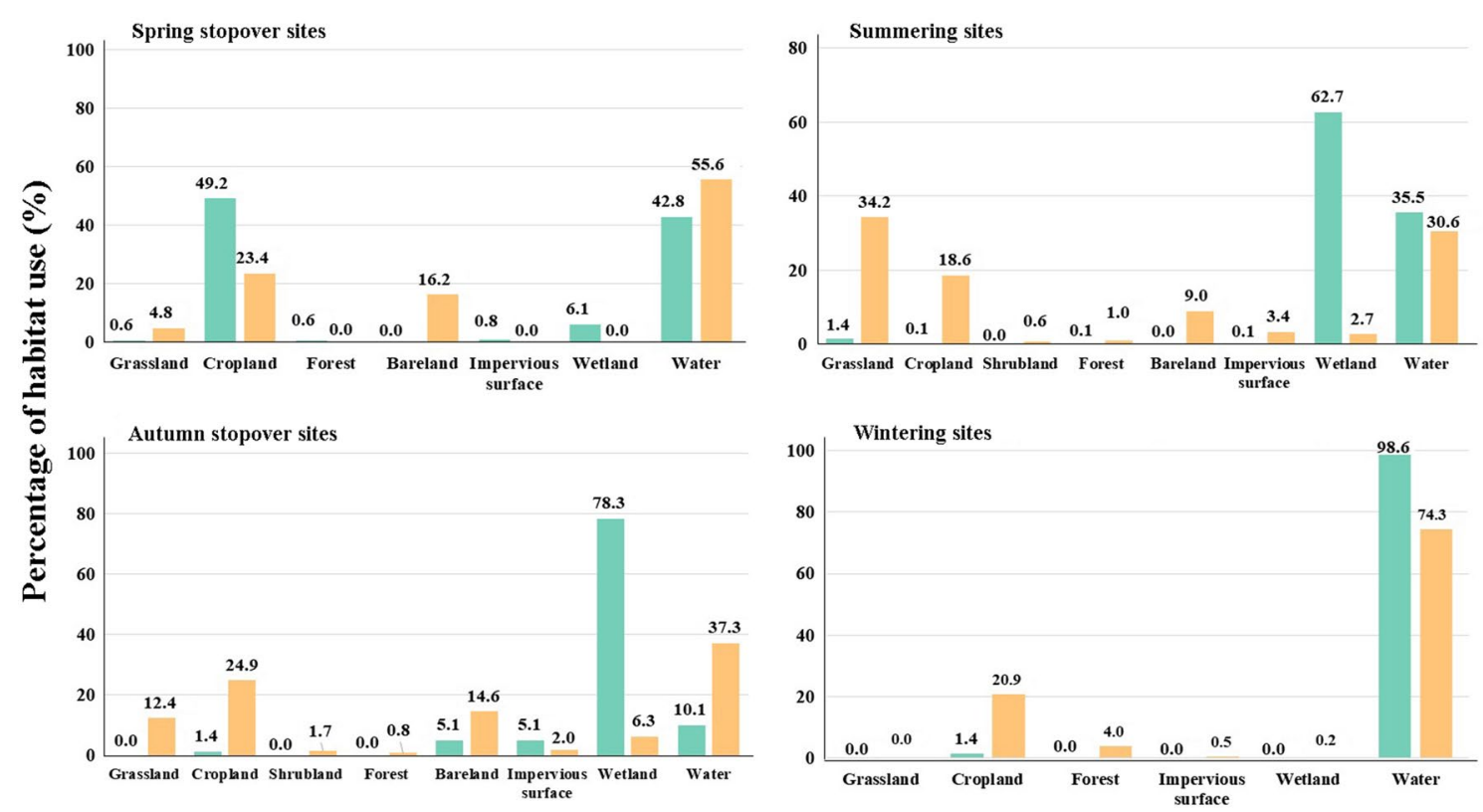

\section{Habitat use types}

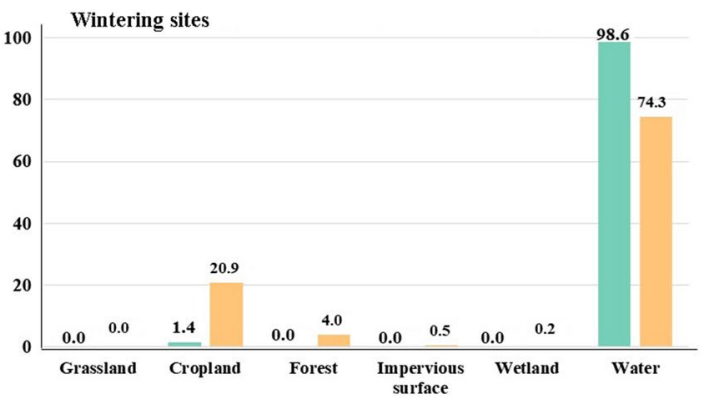

Eastern Mongolia-Yangtze River

= Western Mongolia-Yangtze River

Fig. 5 Habitat use of the Eurasian Spoonbill wintering on the Yangtze River in their spring migration stopover sites, summering sites, autumn migration stopover sites and wintering sites 


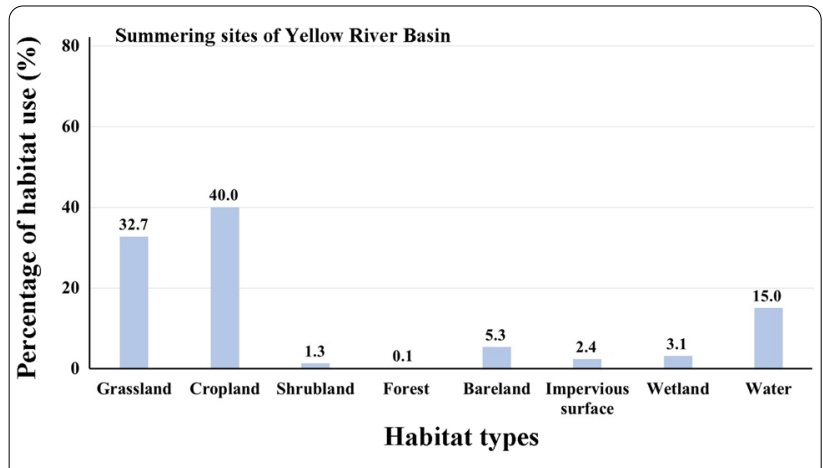

Fig. 6 Habitat use of western Mongolia-Yangtze River individuals $(n=2)$ in the summering area of the Yellow River Basin

taken by one individual in spring and autumn differed substantially. According to a study conducted in wintering areas (Sullender et al. 2016), Eurasian Spoonbills spent $36.4 \%$ of their time foraging, and they prefer foraging areas with water depths of 28.1-36.6 cm. Hence, it is possible that the young birds changed their habitats simply to seek better foraging areas, although how much this was due to inexperience, poor weather conditions or the need to follow different routes in different seasons remains unknown until it is possible to chart many more such migration routes to confirm the frequency of such patterns.

It is extremely difficult to draw meaningful conclusions about migration timing and speed from so few tracked individuals, but the duration of migration stopovers of our tracked sample was highly variable. Stopover duration is likely related to the body condition of the individual and the feeding opportunities to which it is exposed in time and space. Comparing data on autumn migration duration, stopover duration and migration speed, the single Inner Mongolia bird took longer to complete autumn migration than those that took the other two migration routes. This individual also visited more stopover sites with longer stopover time on spring migration compared to those using other routes. However, we urgently need data from more tagged individuals before we can conclude that differences in stopover frequency and overall migration speed are due to differences in migration strategy or in the quality and availability of suitable habitat of birds following these different routes. Nevertheless, it does seem the case that across all migration routes, migration duration in autumn was longer, mainly due to prolonged stopover durations, than in spring, which is consistent with the Oriental Stork (Ciconia neomycin) (Fan et al. 2020) and the classical theory (Kokko 1999). In a study of Central European populations (Pigniczki et al. 2016), the stopover duration of autumn migration (mean $\pm \mathrm{SD}=5.7 \pm 1.0$ days) was longer than that of spring migration ( $3.9 \pm 1.2$ days), which is similar to our results, although our migration durations were much longer (Tables 1 and 2). However, the difference showed in the study was not statistically significant and clear, and we need more tracking studies to confirm these patterns and determine the mechanisms that shape them.

The closely-related and globally threatened Blackfaced Spoonbill (Platalea minor; Sung et al. 2018; Yu et al. 2020) shows similar migration patterns to Eurasian Spoonbills. The Black-faced Spoonbill is currently confined to East and Southeast Asia (Carey et al. 2001). Satellite tracking studies (Jung et al. 2018; Jia et al. 2020; Son et al. 2020) found that Black-faced Spoonbills began to migrate in autumn from mid-October to midNovember, undertaking a maximum migration distance of $1820 \mathrm{~km}$. The longest migration duration for that species was 34 days. The Black-faced Spoonbills usually use 1 to 3 stopover sites during migration, where they remain for 1 to 2 days (although up to 31 days; Y.W. Chen et al. 2021). These are especially similar to the migration habits shown by the Eurasian Spoonbills captured at the Naoli River. We currently know little about the potential for competition and other interactions between these two specialist waterbirds and it would be interesting in the future to compare the migration, diet, habitat use, and ecological niche overlap between Eurasian Spoonbill and Black-faced Spoonbill. Tracking studies of other Ciconiiformes species show contrasting strategies, for instance, Polish tagged Night Herons (Nycticorax nycticorax) were found to spend longer periods (mean 17 days) at each of their migration stopover sites (Ledwoń and Betleja 2015), while tracked Grey Herons (Ardea cinerea) migrated without stopovers (Ye et al. 2018). The reasons behind the differences in frequency and duration of migration stopovers between these species in relation to their food availability need further exploration.

We found 45 stop sites where the stop duration was less than 2 days. These stop durations were not long, so although we might consider they were exploratory, for drinking, resting or preening, it is possible that such halts during migration could potentially also be important for the birds to replenish energy during the migration process. Although ES08 did not stop at all during the spring migration, all other individuals stopped frequently during both of their migrations, perhaps because they did not accumulate sufficient energy stores on their stopover sites, wintering or summering areas to sustain them during migration, or simply because they were sampling potential stopover sites along the route. It is perhaps relevant that ES10 probably died next to a fish pond on the wintering area in May 2019, which might reflect 

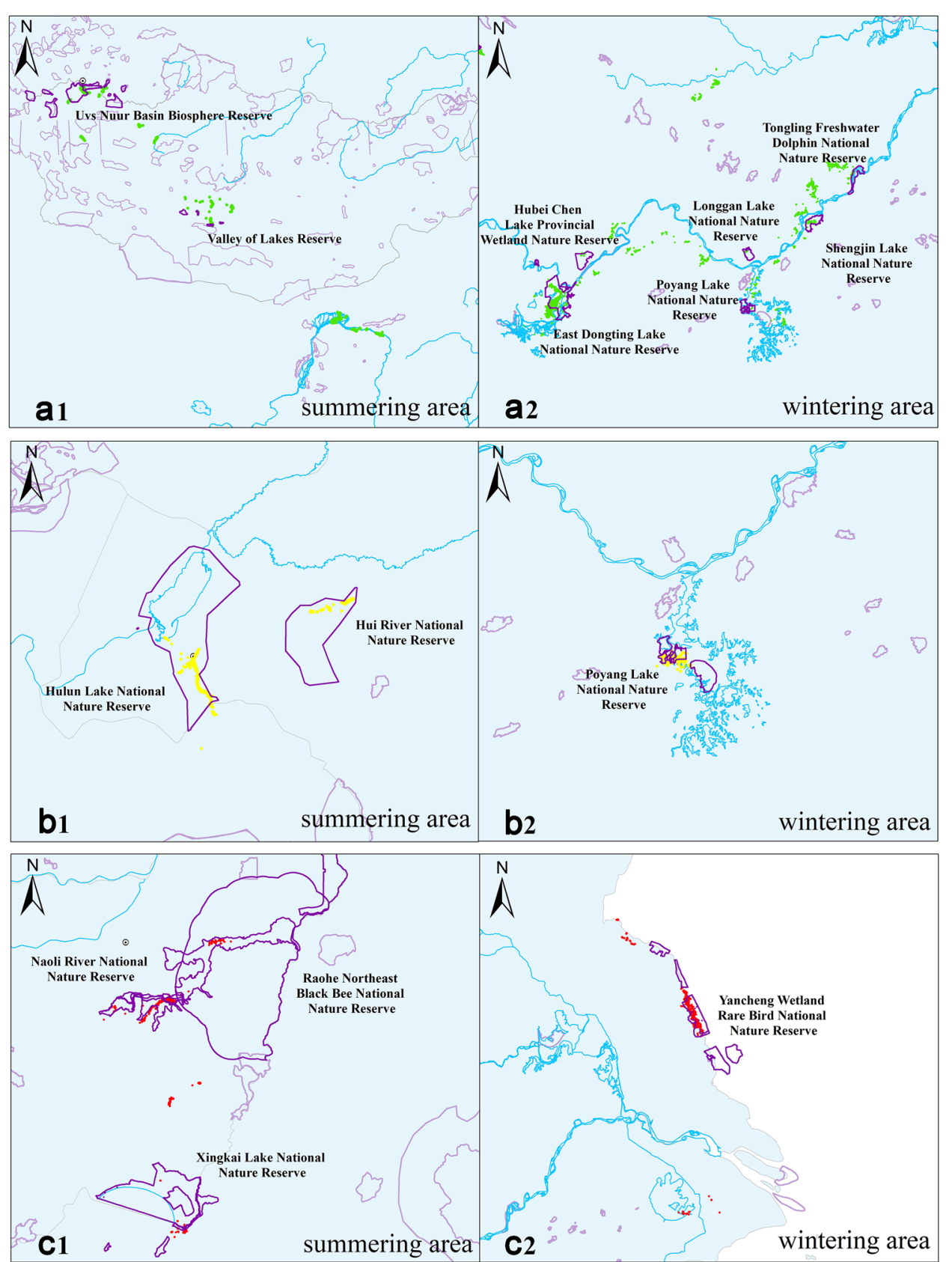

Fig. 7 Maps showing the current extent of protected areas (outlined in purple, with those used by birds shown in darker purple) used by telemetry tagged Eurasian Spoonbills (indicated by different coloured dots) marked at the three discrete breeding areas. Left maps show summer distributions, right maps show the situation in winter in China. Top maps (a 1 and $\mathbf{a} 2$ ) show the summering and wintering areas of birds that summered in western Mongolian, middle maps (b1 and $\mathbf{b} 2$ ) show the summering and wintering areas of birds that summered in Inner Mongolia, and lower maps (c1 and $\mathbf{c} 2$ ) show the summering and wintering areas of birds that wintered in Jiangsu coast, China. Green dots represent individual positions of birds marked in western Mongolia; yellow dots represent the bird marked in Inner Mongolia; red dots represent those wintering along the Jiangsu coast of China

lack of energy stores and an inability to locally replenish these in this bird.

Not surprisingly, Eurasian Spoonbills predominantly utilize water and wetland habitats throughout the annual cycle. This is consistent with the feeding habits used by Eurasian Spoonbills, which mainly forage on fish and crustaceans (Aguilera et al. 1996) and their general behavior that also involves resting, preening and indulging in 
social activities in shallow water (Lok et al. 2013; Sullender et al. 2016). What is interesting is the degree to which some of the tagged birds exploited croplands. Many areas in Yellow River and Yangtze River Basins support intensive rice production, which requires intensive irrigation and a reliable source of water supply that inevitably means such areas are associated with major floodplains, rivers and wetlands. Two of the sub-adult birds from the western Mongolian breeding area that summered in the Yellow River Basin (Fig. 6) showed highest rates of use of cropland (40.0\%), followed by grassland (32.7\%) and open water (15.0\%). Birds from the western Mongolian breeding areas also used croplands and grassland in winter in the Yangtze River Basin as well. While such behavior flexibility suggests an adaptability to exploit novel food resources in new artificial habitats, the use of agricultural habitats is likely to expose Eurasian Spoonbills more to the effects of pesticides and contaminants than perhaps would be the case in natural floodplain wetlands. The use of such artificial habitats may also be an indication of the local loss and/or degradation of natural wetland ecosystems along the network of sites these birds use in their annual cycle.

There is no doubt that the Eurasian Spoonbill enjoys better conservation status than the Black-faced Spoonbill, because of its wider geographical distribution and abundance. These results have also shown a greater complexity in potential biogeographical population structure and diversity in breeding provenance and migration corridors that also suggest a greater robustness to ecological change than the rarer species. However, this does not imply that Eurasian Spoonbills are not threatened in East Asia, especially as the results of our tracking underline deficiencies in the protected areas network to adequately safeguard sites and habitats used by all Chinese wintering birds. The finding that some birds are highly reliant upon croplands also poses questions about the longterm viability of these patterns that need further investigation. We also emphasise that these results stem from tagged juveniles marked on breeding areas, which likely have relatively low survival rates and introduce sources of bias, as we have discussed above. For these reasons we urge further tracking of individuals of all ages, improved wintering surveys to effectively track populations and more ecological studies to determine the food and habitat requirements of the species in this part of its range, to better support the effective protection of this iconic species in the future.

Overall, while the degree of existing protection for sites used by our tagged Eurasian Spoonbills was adequate, there is room for considerable improvement. The sites used by the birds in spring were generally less well protected than at other points in the annual cycle and this could merit further research. Although the spring migration is relatively rapid and the stopover duration time relatively short, it may be that these areas are of disproportional importance to birds preparing for onward migration and, in the case of adults, ultimately preparing to breed. In particular, birds travelling towards the Inner Mongolian breeding areas stopped for prolonged periods in the Yellow River Delta, where they were almost exclusively active outside the boundary of the protected areas. We would urge more survey work on the ground to understand the foraging behaviour, feeding habitat use and roosting areas for these birds to better implement local conservation management and particularly protected area designation to plug this gap in the protection of this species throughout the annual cycle. We recommend further research on Eurasian Spoonbill habitat use and site protection in the future, combining remote sensing, telemetry and field observation.

\section{Conclusions}

This study revealed for the first time the migration routes, stopover patterns and habitat use of Chinese wintering populations of the Eurasian Spoonbill throughout the annual cycle. We are painfully aware of the limitation of the sample size of just ten individuals, so it is clear that we require much further research to determine winter and summer site fidelity of different age classes and the discreteness of the migration corridors that we describe here. We urge continued combined field surveys, longterm color-banding scheme and satellite tracking to describe the migration patterns of a far greater sample of individuals to better illuminate the degree of separation of birds using different migration corridors between discrete breeding and summering areas and their respective winter quarters.

\section{Supplementary Information}

The online version contains supplementary material available at https://doi. org/10.1186/s40657-021-00302-4.

Additional file 1: Table S1. Summary parameters of individual Eurasian Spoonbills equipped with solar GPS/GSM telemetry devices in 2016 and 2018, only including individuals that completed at least one full migration episode in spring or autumn. Table S2. Summering, wintering and stopover areas and duration of stay for each individual from of Eurasian Spoonbills wintering in China. Table S3. Types of land use classification of Eurasian spoonbills tracked broken down by breeding provenance and stage in the annual cycle. Table S4. Proportion of positions used by tracked Eurasian Spoonbill falling within protected areas, broken down by wintering unit groups and stage in the annual cycle.

Additional file 2: Figure S1. Eurasian Spoonbill ES06 migration route map. Figure S2. Eurasian Spoonbill ESO7 migration route map. Figure S3. Eurasian Spoonbill ES08 migration route map. 


\section{Acknowledgements}

Thanks to the capture teams for their work in the field, and thanks to the reserve staff for assisting in the capture work.

\section{Authors' contributions}

$J X, X D, G Z, Y T Y, L C$ and ADF conceived the ideas and designed methodology; NB, ID, QZ, JC and SC collected the data; JX and XD analyzed the data. JX led the writing of the manuscript, with contributions from GZ, YC, LC and ADF. All authors contributed critically to the drafts. All authors read and approved the final manuscript.

\section{Funding}

This study was supported by the National Natural Science Foundation of China (Grant No. 31970433), Youth Innovation Promotion Association, Chinese Academy of Sciences (Grant No. 2020046), China Biodiversity Observation Networks (Sino BON). The funders had no role in study design, data collection and analysis, decision to publish, or preparation of the manuscript.

\section{Availability of data and materials}

The datasets used in the present study are available from the corresponding author on reasonable request.

\section{Declarations}

\section{Ethical approval and consent to participate}

The following information was supplied relating to ethical approvals (i.e. approving body and any reference numbers): The Animal Ethics Committee, Research for Eco-Environmental Sciences, Chinese Academy of Sciences fully approved this study. Approval for bird capture and transmitter deployment in Mongolia was obtained from the Ministry of Nature, Environmental and Tourism of Mongolia (permission number: No. 06/2862). Approval for transmitter deployment at Qixing River and Hulun Lake, China was obtained from the Qixing River National Nature Reserve authorities and Hulun Lake National Nature Reserve Administration.

\section{Consent for publication}

Not applicable.

\section{Competing interests}

The authors declare that they have no competing interests.

\section{Author details \\ ${ }^{1}$ Inner Mongolia Normal University, Hohhot 010000, Inner Mongolia, China. ${ }^{2}$ State Key Laboratory of Urban and Regional Ecology, Research Center for Eco-Environmental Sciences, Chinese Academy of Sciences, Beijing 100085 , China. ${ }^{3}$ University of Chinese Academy of Sciences, Beijing 101408, China. ${ }^{4}$ Wildlife Science and Conservation Center of Mongolia, Undram Plaza 404 toot, Ulaanbaatar 210351, Mongolia. ${ }^{5}$ Heilongjiang Baoqing Qixinhe National Nature Reserve Administration, Baoqing, Heilongjiang 155600, China. ${ }^{6}$ School of Life Sciences, University of Science and Technology of China, Hefei 230026, China. ${ }^{7}$ Hong Kong Bird Watching Society, Hong Kong SAR, China. ${ }^{8}$ Depart- ment of Bioscience, Aarhus University, Grenåvej 14, 8410 Kalø, Denmark. ${ }^{9}$ Institute of Biology, Mongolian Academy of Sciences, 13330 Ulaanbaatar, Mongolia.}

Received: 28 February 2021 Accepted: 10 November 2021

Published online: 04 December 2021

\section{References}

Aguilera E, Ramo C, Claudine dIC. Food and feeding sites of the Eurasian spoonbill (Platalea leucorodia) in southwestern Spain. Colon Waterbirds. 1996;19:159-66.

Barter M. Waterbird survey of the middle and lower Yangtze River floodplain in late January and early February 2004. Beijing: China Forestry Pulishing House; 2004.

Bellisario B. Conserving migration in a changing climate, a case study: the Eurasian spoonbill, Platalea leucorodia leucorodia. Biol Conserv. 2018;217:222-31.
Benhamou S. How to reliably estimate the tortuosity of an animal's path: straightness, sinuosity, or fractal dimension. J Theor Biol. 2004;229:209-20.

BirdLife International. Platalea leucorodia (amended version of 2016 assessment). The IUCN Red List of Threatened Species 2019: e.T22697555A155460986. 2019. https://dx.doi.org/10.2305/IUCN.UK. 2019-3.RLTS.T22697555A155460986.en. Accessed 28 Feb 2021.

Carey G, Chalmers M, Diskin D, Kennerley P, Leader P, Leven M, et al. The avifauna of Hong Kong. Hong Kong: Hong Kong Bird Watching Society; 2001.

Champagnon J, Kralj J, Cano Alonso LS, Sundar KSG. In: Proceedings of the IX workshop of the AEWA Eurasian Spoonbill international expert group. Arles: IUCN-SSC Stork, Ibis and Spoonbill specialist group special publication 2; 2019.

Chen YW, Yu YT, Meng FJ, Deng XQ, Yi KP, Cao L, Fox AD. Migration routes, population status and important sites used by the globally threatened Black-faced Spoonbill Platalea minor: a synthesis of surveys and tracking studies. Avian Research. 2021. (In Press)

El-Hacen E-HM, Overdijk O, Lok T, Olff H, Piersma T. Home range, habitat selection, and foraging rhythm in Mauritanian Spoonbills (Platalea leucorodia balsaci): a satellite tracking study. Waterbirds. 2013;36:277-86.

Enners L, Guse N, Schwemmer P, Chagas ALJ, Voigt CC, Garthe S. Foraging ecology and diet of Eurasian spoonbills (Platalea leucorodia) in the German Wadden Sea. Estuar Coast Shelf S. 2020;233:106539.

Fan S, Zhao Q, Li H, Zhu B, Dong S, Xie Y, et al. Cyclical helping hands: seasonal tailwinds differentially affect migrating Oriental Storks (Ciconia boyciana) travel speed. Avian Res. 2020;11:10

Gong P, Liu H, Zhang M, Li C, Wang J, Huang H, et al. Stable classification with limited sample: transferring a 30-m resolution sample set collected in 2015 to mapping 10-m resolution global land cover in 2017. Sci Bull. 2019;64:370-3.

Jelena K, Antun Z, Tibor M, Otto O. Movements of immature Eurasian Spoonbills Platalea leucorodia from the breeding grounds of the eastern metapopulation in the Pannonian Basin. Waterbirds. 2012;35:239-47.

Jia R, Liu D, Lu J, Zhang G. Wetland destruction on migration routes threatens a breeding population of the endangered black-faced spoonbill (Platalea minor). Glob Ecol Conserv Biol. 2020;23:e01105.

Jung SM, Kang JH, Kim IK, Lee HS, Lee SW, Oh HS. Autumn migration of Blackfaced Spoonbill (Platalea minor) tracked by wild-tracker in East Asia. Kor J Environ Ecol. 2018;32:478-85.

Kokko H. Competition for early arrival in migratory birds. J Anim Ecol. 1999;68:940-50.

Koelzsch A, Mueskens GJDM, Kruckenberg H, Glazov P, Weinzierl R, Nolet BA, et al. Towards a new understanding of migration timing: slower spring than autumn migration in geese reflects different decision rules for stopover use and departure. Oikos. 2016;125:1496-507.

Ledwoń M, Betleja J. Post-breeding migration of Night Herons Nycticorax nycticorax tracked by GPS/GSM transmitters. J Ornithol. 2015;156:313-6.

Li GF. Study on the rhythm of brooding behavior of the Eurasian Spoonbill (Platalea leucorodia) in the reproductive period. Master's Thesis. Harbin: Northeast Forestry University; 2016. (in Chinese)

Lok T, Overdijk O, Tinbergen JM, Piersma T. The paradox of spoonbill migration: most birds travel to where survival rates are lowest. Anim Behav. 2011;82:837-44.

Lok T, Overdijk O, Piersma T. Migration tendency delays distributional response to differential survival prospects along a flyway. Am Nat. 2013;181:520-31.

Nilsson C, Klaassen RHG, Alerstam T. Differences in speed and duration of bird migration between spring and autumn. Am Nat. 2013;181:837-45.

Piersma T, van der Velde M, El-Hacen E-HM, LokT, Overdijk O. Molecular verification of the subspecies status of the Mauritanian Spoonbill Platalea leucorodia balsaci. Ardea. 2012;100:131-6.

Pigniczki C, Vegvari Z. Dispersal of the Central European population of the Eurasian Spoonbill Platalea leucorodia. Ardeola. 2015;62:219-36.

Pigniczki C, Kralj J, Volponi S, Žuljević A, Dakhli M-A, Mikuska T, et al. Migration routes and stopover sites of the Eurasian Spoonbill (Platalea leucorodia) between the Carpathian Basin and wintering areas. Ornis Hungarica. 2016;24:128-49.

R Development Core Team. R: A Language and Environment for Statistical Computing. R Foundation for Statistical Computing, Vienna, Austria. 2020 https://www.rproject.org. Accessed 5 Mar 2020. 
Son SJ, Kang JH, Lee SK, Kim IK, Yoo JC. Breeding and wintering home ranges of the black-faced spoonbill Platalea minor. J Asia-Pac Biodivers. 2020;13:7-12.

Sullender BK, Barzen J, Silbernagel J. Foraging success and habitat selection of the Eurasian Spoonbill (Platalea leucorodia) at Poyang Lake. China Waterbirds. 2016;39:356-64.

Sung YH, Tse IWL, Yu YT. Population trends of the Black-faced Spoonbill Platalea minor: analysis of data from international synchronised censuses. Bird Conserv Int. 2018;28:157-67.

Veen J, Overdijk O, Veen T. The diet of an endemic subspecies of the Eurasian Spoonbill Platalea leucorodia balsaci, breeding at the Banc d'Arguin. Mauritania Ardea. 2012;100:123-30.

Wang X, Cao L, Bysykatova I, Xu Z, Rozenfeld S, Jeong W, et al. The Far East taiga forest: unrecognized inhospitable terrain for migrating Arctic-nesting waterbirds. PeerJ. 2018;6:e4353.

UNEP WCMC. World database on protected areas user manual 1.5. 2017. https://www.unep-wcmc.org/resources-and-data/world-database-onprotected-areas-user-manual.
Wetlands International. Waterbird Population Estimates 5 2021; 2021. http:// wpe.wetlands.org/search?form\%5Bspecies\%5D=Eurasian+Spoonbill\& form\%5Bpopulation\%5D=\&form\%5Bpublication\%5D=5.

Xi JR. A study on the population size and migration strategy of the Eurasian Spoonbill (Platalea leucorodia) overwintering in China. Master's Thesis. Huhhot: Inner Mongolia Normal University; 2021. (in Chinese)

Ye X, Xu Z, Aharon-Rotman Y, Yu H, Cao L. First description of Grey Heron Ardea cinerea migration recorded by GPS/GSM transmitter. Ornithol Sci. 2018;17:223-8

Yu YT, Li CH, Tse IWL, Fong HHN. International Black-faced Spoonbill Census 2020. Hong Kong: Black-faced Spoonbill Research Group, The Hong Kong Bird Watching Society; 2020

Zhang YA. Comparative study on the habitats of the Eurasian Spoonbill (Platalea leucorodia) in different periods. Master's Thesis. Harbin: Northeast Forestry University; 2018. (in Chinese)
Ready to submit your research? Choose BMC and benefit from:

- fast, convenient online submission

- thorough peer review by experienced researchers in your field

- rapid publication on acceptance

- support for research data, including large and complex data types

- gold Open Access which fosters wider collaboration and increased citations

- maximum visibility for your research: over $100 \mathrm{M}$ website views per year

At BMC, research is always in progress.

Learn more biomedcentral.com/submissions 